\title{
Article \\ Efficacy of Miniscrews in Gaining Prosthetic Space for a Dental Implant to Replace the Mandibular First Molar: A Case Series
}

\author{
Ana Roig-Vanaclocha, Naia Bustamante-Hernández *, Maria Fernanda Solá-Ruíz (D), Carla Fons-Badal, \\ Eduardo Selva-Otaolaurruchi and Rubén Agustín-Panadero
}

check for

updates

Citation: Roig-Vanaclocha, A.; Bustamante-Hernández, N.; Solá-Ruíz, M.F.; Fons-Badal, C.; Selva-Otaolaurruchi, E.;

Agustín-Panadero, R. Efficacy of Miniscrews in Gaining Prosthetic Space for a Dental Implant to Replace the Mandibular First Molar: A Case Series. Appl. Sci. 2021, 11, 607. http://doi.org/10.3390/app11020607

Received: 12 November 2020 Accepted: 6 January 2021 Published: 10 January 2021

Publisher's Note: MDPI stays neutral with regard to jurisdictional clai$\mathrm{ms}$ in published maps and institutional affiliations

Copyright: (C) 2021 by the authors. Licensee MDPI, Basel, Switzerland. This article is an open access article distributed under the terms and conditions of the Creative Commons Attribution (CC BY) license (https:// creativecommons.org/licenses/by/ $4.0 /)$.
Department of Stomatology, Faculty of Medicine and Dentistry, University of Valencia, 46010 Valencia, Spain; ana.roig@uv.es (A.R.-V.); m.fernanda.sola@uv.es (M.F.S.-R.); carla.fons@uv.es (C.F.-B.); eduardo.j.selva@uv.es (E.S.-O.); ruben.agustin@uv.es (R.A.-P.)

* Correspondence: naiabustamante@gmail.com

Abstract: Background: The objective of this case series was to evaluate the efficacy of miniscrews to upright the lower second molar as a result of early loss of the lower first molar in order to permit rehabilitation by means of an implant-supported single crown. Methods: The case series included ten patients who each received a miniscrew placed distal of the second molar in order to straighten the tooth; the prosthetic space gained (sufficient to allow implant placement in the edentulous space) and the change in angulation obtained were analyzed. The changes produced by miniscrews were evaluated in radiographs. Results: Statistical analysis identified significant improvements in angulation ( $p=0.005)$ and significant amounts of space gained $(p=0.005)$ as well as a strong correlation between these two parameters $(\mathrm{r}=-0.93 ; p<0.001)$. Conclusions: The use of miniscrews alone without the intervention of other orthodontic methods to straighten a mesialized lower second molar in order to replace a missing first molar with an implant significantly improves both the angulation of the molar and the prosthetic space available.

Keywords: miniscrews; reduced prosthetic space; dental implant; implant-supported single crown

\section{Introduction}

First molars are the first permanent teeth to erupt and play a fundamental role in maintaining the shape of the dental arch and adequate occlusal schemes. The early loss of mandibular first molars is fairly common among adult patients, as these teeth are present in the oral cavity for longer and are thus more prone to caries, endodontic and periodontal problems, or vertical fracture [1], all due to poor oral hygiene maintenance [2,3]. The premature loss of a permanent first molar must be dealt with immediately to avoid functional and anatomical disorders. As a result of first molar loss, mesial inclination and rotation of the adjacent teeth can occur, which causes a reduction in the prosthetic space available for rehabilitation [2-4]. If the inclination is not corrected, this aggravates periodontal problems in mesially impacted molars, causing inflammation, angular bone loss, a periodontal pocket on the mesial aspect of the second molar, and increased plaque retention leading to interproximal caries [5-8].

Various treatment options are available for substituting single posterior teeth: a removable partial prosthesis, a tooth-supported fixed single or partial denture (FPD), or an implant-supported single or FPD. Lately, the latter option has become the treatment of choice for replacing single missing teeth, as it provides demonstrably good clinical outcomes [9] while preserving the teeth adjacent to the edentulous space, creating better conditions for oral hygiene maintenance, reducing the sensitivity of the adjacent teeth, improving esthetics, and preserving bone [10].

Inclined molars cause problems, especially when it comes to planning the replacement of missing teeth. Placing an implant in the edentulous space demands a series of conditions including adequate bone volume, healthy adjacent teeth, and sufficient mesiodistal space 
between the adjoining teeth. In cases in which the mesiodistal first molar space is reduced, various techniques can be used to straighten the inclined second molar, move it to its correct position, and obtain the prosthetic space needed. Recently, the use of miniscrews has been introduced for this purpose $[1,11,12]$.

The minimum prosthetic space needed beside adjoining teeth to replace a lower first molar is $6.5 \mathrm{~mm}$, as the mesiodistal width of the tooth usually ranges between 8 and $12 \mathrm{~mm}$. Spaces of less than $6.5 \mathrm{~mm}$ do not permit prosthodontic rehabilitation of the missing molar, as it does not provide enough room for the implant supported prosthetic crown. At the same time, a space larger than $12 \mathrm{~mm}$ needs two adjoining implants to support a single restoration to reduce the forces exerted on the cantilever extending to mesial and distal and to reduce the risk of abutment screw loosening [13].

Miniscrews or micro-implants are small temporary fixtures inserted in bone to use as anchorage during orthodontic treatment [14]. They are made from pure titanium or a titanium alloy and have diameters of 1-2 $\mathrm{mm}$ and a variable length of between 6 and $20 \mathrm{~mm}$. They remain stable throughout orthodontic treatment, only suffering a minimal loss of anchorage and thus are very effective. This relatively new concept of skeletal anchorage is simpler, smaller, less invasive, and more economical. Moreover, miniscrews do not require a long interval between placement and force application since loading can commence immediately after placement [15]. The use of miniscrews provides effective management of dental movements in both anteroposterior and vertical directions [16-19].

Miniscrews can be used in ways that impact on either the whole or part of the dental arch. Straightening the second molar and bringing it to its correct position normalizes function and stabilizes periodontal conditions [20]. It makes it possible to position the root perpendicular to the occlusal plane so that it is able to withstand occlusal forces and place the prosthesis' insertion plane parallel to the tooth axis [21,22]. It also generates sufficient space for replacing the missing tooth.

The aim of this clinical case series was to evaluate the efficacy of miniscrews uprighting the lower second molar, mesialized as result of early loss of the permanent lower first molar, by analyzing the prosthetic space gained and the change in angulation produced after movement, and to determine whether or not there is a correlation between the amount of movement and the prosthetic space gained.

The study's working hypotheses were that (Hypothesis 1) miniscrews placed in the retromolar area of the lower second molar would straighten/improve angulation using the orthodontic mechanics applying miniscrew as anchorage of the mesio-inclined second molar; and (Hypothesis 2) miniscrew mechanics would increase the prosthetic space available, allowing the replacement of the missing first molar.

\section{Materials and Methods}

This case series included 10 patients who had lost a lower first molar, accompanied by a loss of space between the adjacent teeth, preventing replacement by an implant-supported single crown. The patients were treated at the Prosthodontic and Occlusion Unit, University of Valencia (Carrer Gascó Oliag 1, 46010, Valencia, Spain). All patients were given complete information about the benefits and the risks of treatment and gave their informed consent for their case to be included in the series and undergo analysis. The study protocol was approved by the University of Valencia Ethics Committee for Research Involving Humans (Procedure $\left.\mathrm{N}^{\circ} \mathrm{H} 1510309932301\right)$. All patients were treated between September 2019 and June 2020.

\subsection{Inclusion/Exclusion Criteria}

Inclusion criteria were as follows: adult patients aged over 18 years, non-smokers, presenting good oral hygiene maintenance, without systemic contra-indications, periodontally healthy patients or with managed periodontal disease, presenting a missing lower first molar, and mesialization of the second molar so that it invaded the space formerly occupied by the first molar. 
Exclusion criteria were: patients aged younger than 18 years, in poor general or oral health, smokers, patients with systemic diseases or in receipt of drugs that might interfere in healing or blood clotting, and patients presenting molars with periodontal mobility.

\subsection{Miniscrew Insertion}

All miniscrews and implants were placed by the same clinician $(\mathrm{R}-\mathrm{V}, \mathrm{A})$. The miniscrews used were low profile, self-tapping Optimus (Osteonic, Seoul, South Korea) Model $\mathrm{O}$, of $1.6 \mathrm{~mm}$ diameter and $11 \mathrm{~mm}$ length, made from biocompatible TiAl6V4 titanium alloy. These miniscrews are designed with a flat hexagonal head, a mucosal protective collar, and smooth, polished transmucosal surface to avoid gingival inflammation, as well as an area of buttress thread to enhance pull-out strength.

Miniscrew insertion was performed under local anesthetic at the host area. As these were self-tapping screws, it was not necessary to perform flap surgery to create access or to drill cortical bone tissue, as the screws were placed transmucosally with an electric counter-angle with torque limit (25 N) (NSK, Tochigi, Japan).

The miniscrews were placed distal of the lower second molar in the middle of the bone crest in order to straighten the molar and gain the space required for endosseous implant placement to replace the missing first molar. The miniscrews used were $1.6 \mathrm{~mm}$ wide and $11 \mathrm{~mm}$ in length. At least $4.6 \mathrm{~mm}$ wide and more than $11 \mathrm{~mm}$ in length should be needed to use the miniscrew as a treatment option. The mesial inclination of the second molar is accompanied by the same inclination of the third molar, invading the prosthetic space of the first molar absent. To straighten the second molar and obtain enough space to replenish the first molar absent, the technique with miniscrews requires the extraction of the third molar inclined, favoring two objectives: obtain space for the placement of the miniscrew in the retromolar trigone and obtain the necessary space for the straightening of the second molar. All the third molars present were extracted for the straightening of the second molar. The miniscrew was placed so that the thread area was within the bone, while the transgingival portion and the head remained visible (Figure 1A,B).

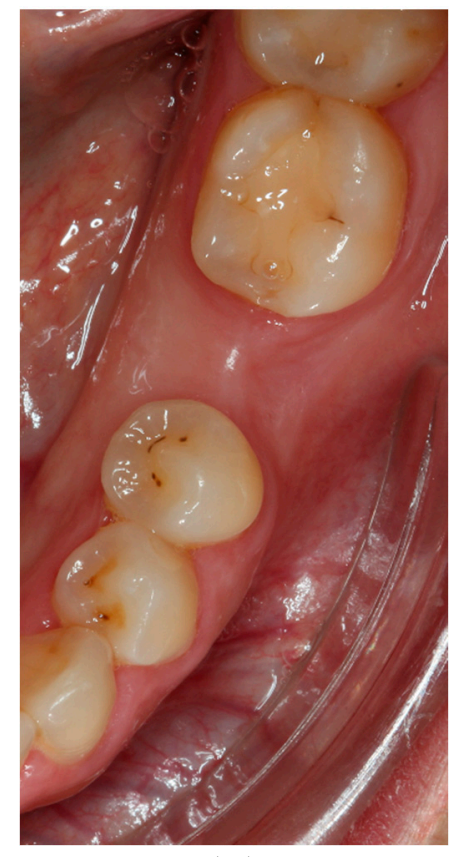

(A)

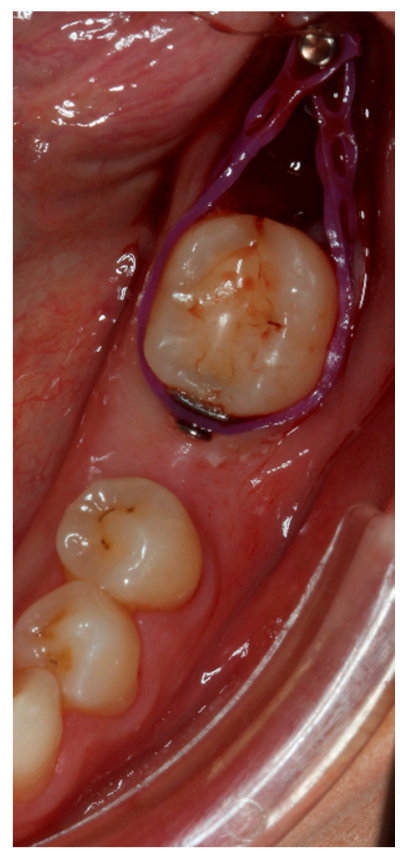

(B)

Figure 1. (A) Initial case with lack of available mesiodistal space for the replacement of the missing tooth. (B) Case after extraction of third molar and insertion of the miniscrew attached with an elastic chain to a mesial button of the tooth to upright. 
As soon as the screw was inserted, an extraoral radiograph was taken to check that insertion was carried out correctly. Ideally, this type of treatment should be performed on bone types I and II, including type III in some cases, but it would not be advisable in type IV for a fully trabecular bone. However, once the miniscrew is placed, its primary stability should be checked by applying the traction force to distal. A $0.12 \%$ chlorhexidine gel (GUM, John O. Butler/Sunstar, Chicago, IL, USA) was applied as disinfectant. No antibiotics or analgesics were prescribed. Immediately after miniscrew insertion and once the miniscrew load had started with the tensile forces, a mesial button (3M, St. Paul, MN, USA) was placed with an elastic chain (GC Orthodontics, Breckerfeld, Germany) surrounding the entire crown to straighten the tooth that would exert the necessary force to straighten the second molar. The button was cemented to the mesial surface of the inclined second molar. The inclined tooth was etched with $37 \%$ orthophosphoric acid etching gel (Total Etch, Ivoclar Vivadent, Amherst, NY, USA) for $30 \mathrm{~s}$, and adhesive was applied to the dental enamel (Adhese Universal, Ivoclar Vivadent) and polymerized for $10 \mathrm{~s}$ (Bluephase G2 curing light, Ivoclar Vivadent). It was cemented using a flowable particulate filler composite (G-aenial Universal Injectable A2, GC America, Alsip, IL, USA) and light cured for $40 \mathrm{~s}$. Once the button was cemented, an elastic chain was attached to the mesial button and to the miniscrew by the ends of the chain in order to upright the molar. The elastic chain was usually advanced a buttonhole every 15 days until maximum straightening and adequate prosthetic space were obtained (Figure 2).

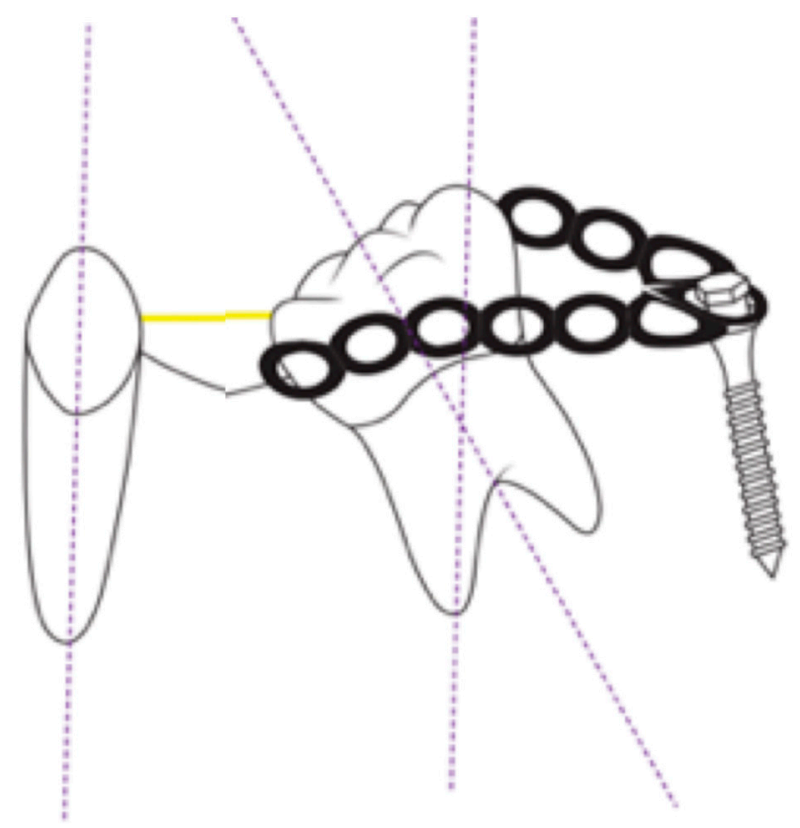

Figure 2. Illustrative scheme of the miniscrew straightening the tooth by using the mesial button attached to two elastic chains.

Occlusion forces should also be relieved (by using occlusal stops or by relieving the antagonist) during the treatment period. The average duration to get molar uprighting was usually 2-3 months. In this case series, none of the miniscrews suffered loss of mechanical anchorage until the end of the straightening of the inclined molars.

\subsection{Radiographic Analysis}

Evaluation of the efficacy of miniscrew treatment was performed using orthopantomographs taken before and after treatment. The orthopantomographs were taken at the Department of Radiology attached to the University of Valencia Dental Clinic by the department staff. Measurements were always taken by the same operator to avoid any discrepancies derived from different interpretations of the radiographs. To avoid possible radiographic distortion, the length (in millimeters) of the miniscrew determined by the 
manufacturer was used as a reference value; all radiographs were scaled according to this length. The amount of prosthetic space obtained was determined by calculating the difference between baseline measurements taken at the moment when the miniscrew was placed (T0) and measurements taken after implant insertion (T1). Measurements were taken using AutoCAD ${ }^{\circledR}$ software (Autodesk Inc., San Rafael, CA, USA). To evaluate the prosthetic space gained as a result of treatment, the distance from the most distal point of the second premolar crown to the most mesial point of the second molar crown was measured at both evaluation times (T0 and T1, post- and pre-treatment) comparing the measurements obtained (Figure 3A,B).

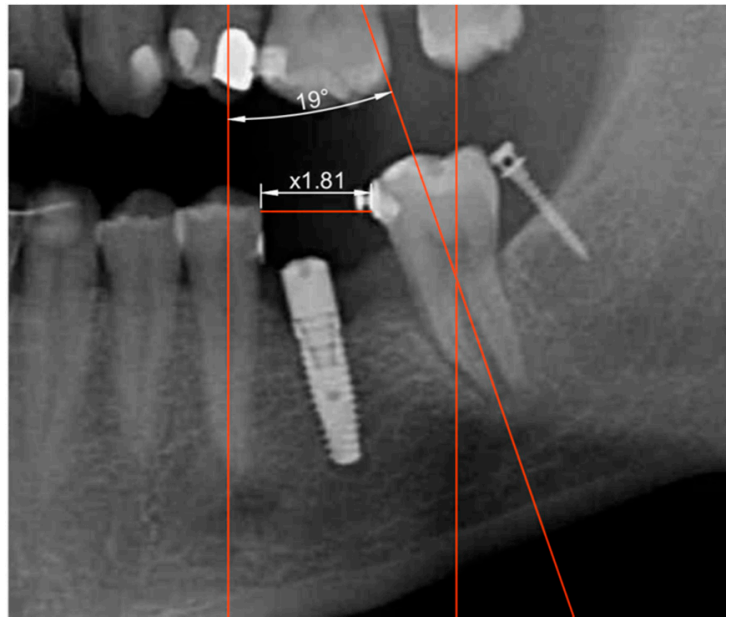

(A)

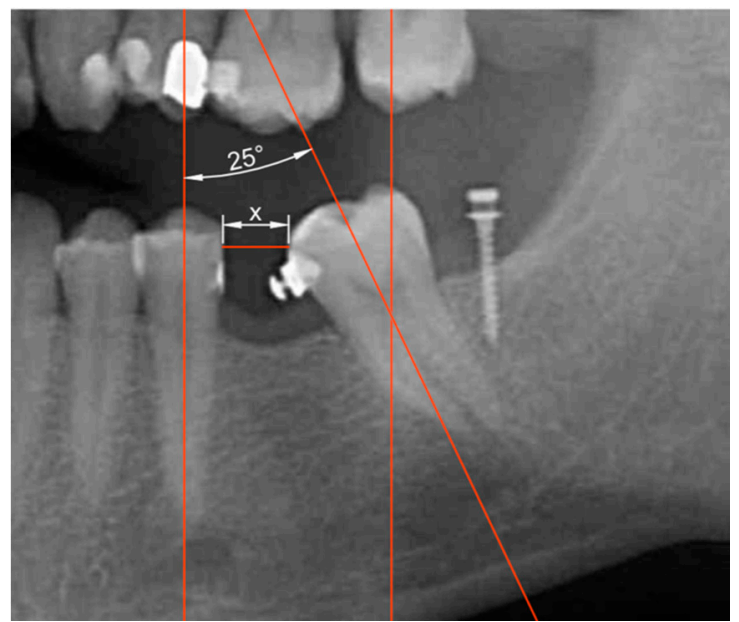

(B)

Figure 3. (A) Illustration of pre-treatment angulation and distance measurements taken from radiographs. (B) Illustration of post-treatment angulation and distance measurements taken from radiographs.

To determine the prosthetic space created, the measurement schema described below was followed, in which dashed lines represent angulation measurements and continuous lines represent distance.

When the radiographs were scaled, measurements were taken as follows:

Angles measured before and after treatment were compared to evaluate changes in second molar angulation by tracing the vertical axes of the second premolar and the second molar on the radiographs. A line was drawn parallel to the second premolar axis passing through the second molar furcation. Finally, the angulations between the second molar axis and the second premolar axis were compared in pre-treatment and post-treatment radiographs.

\subsection{Statistical Analysis}

Preliminary analysis of the data was performed calculating descriptive statistics prior to relating the variables evaluated. Inferential analysis included the following statistical tests:

The Wilcoxon test was used to analyze changes in the distribution of parameters deriving from treatment. Spearman's non-linear correlation coefficient was applied to estimate the degree of association between the changes in angulation and prosthetic space gained. Linear and non-linear regression models were estimated to obtain a predictive equation of space gained and expected space-gain. The significance level applied in analysis was $5 \%(\alpha=0.05)$.

\section{Results}

\subsection{Study Population}

This case series included ten patients, who each received one miniscrew (eight women and two men with a mean age of $42.7 \pm 10.6$ years). 
Having completed miniscrew treatment and analyzed the outcomes in radiographs, the following changes were recorded: changes in prosthetic space or distance, changes in angulation, and relationship between changes in distance and angulation.

\subsection{Changes in Prosthetic Space}

The first variable analyzed determined whether the use of miniscrews increased the prosthetic space available for replacement of the missing first molar by means of an implant. To do this, the difference between the initial distance (T0) and the final distance (T1) was calculated

The median initial distance was $5.50 \mathrm{~mm}$ (2.4-15.5), which increased to $12.4 \mathrm{~mm}(8.0-21.4)$ as a result of treatment. The median space gained was $6.39 \mathrm{~mm}(3.1-16.7)$ (Table 1).

Table 1. Changes in prosthetic space.

\begin{tabular}{cccccccc}
\hline & N & Mean & Standard Deviation & Minimum & Maximum & Median & 95\% CI Median \\
\hline Distance T0 & 10 & 5.98 & 3.64 & 2.40 & 15.50 & 5.50 & $3.20-6.80$ \\
Distance T1 & 10 & 14.11 & 5.03 & 8.04 & 21.43 & 12.41 & $9.18-20.6$ \\
Distance T1-T0 & 10 & 8.13 & 4.53 & 3.14 & 16.73 & 6.39 & $4.91-13.4$ \\
\hline
\end{tabular}

The Wilcoxon test confirmed that the space gained was statistically significant $(p=0.005)$. The confidence interval for the median concluded that half the sample gained over $4.9 \mathrm{~mm}$ with a $97.5 \%$ probability.

\subsection{Changes in Angulation}

The other variable analyzed determined whether miniscrews placed in the lower second retromolar area improved the angulation of the mesioinclined second molar.

The median (range) pre-treatment angle was $35^{\circ}(22-48)$, which decreased to $11^{\circ}$ post-treatment (5-19). The mean reduction in angulation was $24.5^{\circ}(6-36)$ (Table 2).

Table 2. Changes in angulation.

\begin{tabular}{cccccccc}
\hline & N & Mean & Standard Deviation & Minimum & Maximum & Median & Median CI 95\% \\
\hline Angle T0 & 10 & 35.30 & 8.83 & 22.00 & 48.00 & 35.00 & $25-47$ \\
Angle T1 & 10 & 11.10 & 4.91 & 5.00 & 19.00 & 11.00 & $5-16$ \\
Angle T1-T0 & 10 & -24.20 & 10.11 & -36.00 & -6.00 & -24.50 & $-35-16$ \\
\hline
\end{tabular}

The Wilcoxon test confirmed that miniscrew mechanics produced a significant reduction in angulation $(p=0.005)$. The median confidence interval concluded that half the sample underwent improvements in angulation of over $16^{\circ}$ with a probability of $97.5 \%$.

\subsection{Relationship between Changes in Distance and Angulation}

The data obtained were analyzed to determine whether there was a direct relationship between changes in angulation and the amount of prosthetic space gained.

The scatter plot below represents the space gained in relation to reductions in angulation (Figure 4).

It is clear from the scatter graph that the greater the reduction in angulation was (points towards the left on the horizontal axis), the greater the prosthetic space gained was (points higher up in vertical direction).

Spearman's correlation coefficient was $r=-0.93$ and was statistically significant $(p<0.001)$, pointing to a very strong correlation.

As this was a case series, quadratic adjustment was performed, as this would provide a fairly precise adjustment. The adjustment showed significance $(p<0.05)$ applying the following equation to obtain an approximate estimate:

Gain in space $=8.14+0.60$ change in angulation $+0.02(\text { change in angulation })^{2}$ 
When the change in angulation was entered in the equation, this generated the expected gain in space.

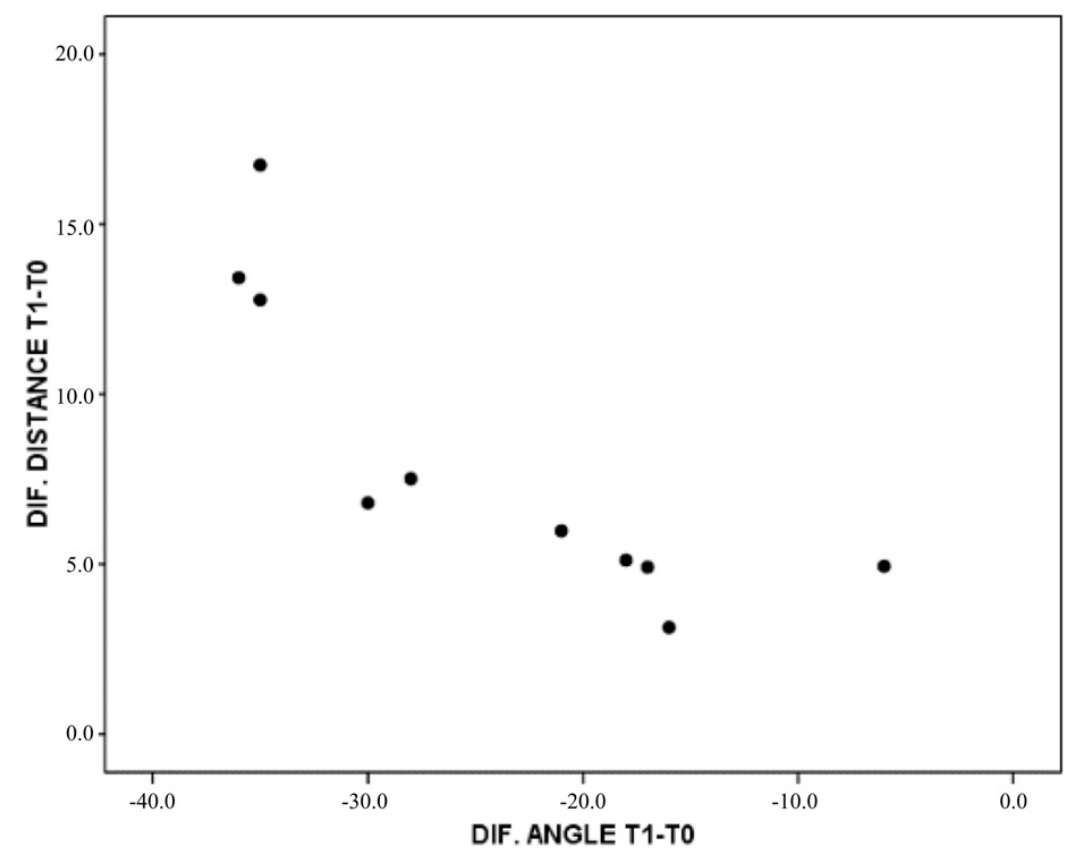

Figure 4. Prosthetic space gained in relation to reductions in angulation.

\section{Discussion}

This case series analyzed 10 patients who had lost lower first molars and presented mesialization of the second molar. The study objectives were to measure the changes in angulation and the prosthetic space gained as a result of miniscrew mechanics using standardized pre- and post-treatment orthopantomographs. The same radiological technique has been used in other study by Musilli et al. [23], the latter complemented by lateral teleradiography of the cranium in order to perform cephalometric analysis. Standardized radiographs are frequently used in dental research for a range of purposes. After scaling the radiographs, the images obtained were processed using software to take measurements of changes in the prosthetic space available and angulation, as described by Piao et al. [24], Peñarrocha-Diago et al. [25], Spinato et al. [26], and Agustín-Panadero et al. [27,28], who used various software functions for purposes similar to the present work.

Measurements were taken using the same method in all cases. Angulation was analyzed by tracing a line along the vertical axes of the premolar and the second molar, afterwards tracing a line parallel to the premolar axis passing though the second molar furcation. To measure increases in prosthetic space, the distance between the most distal point of the premolar crown and the most mesial point on the second molar was measured. No other study in the literature has measured both angulation and prosthetic space together.

All ten cases were treated by means of the same technique. A miniscrew was inserted in the retromolar area, placing a button on the mesial or the vestibular aspect of the second molar crown; the same technique has been described in several other studies [23,29-32].

The literature includes several works that describe miniscrews placed in mesial areas with the same objective as the present case series [23,29]. Although the use of miniscrews in retromolar areas is common, soft tissue thickness and the patient's oral health must be assessed in order to select the most suitable position to ensure a successful outcome.

According to the present results, the first hypothesis $\left(\mathrm{H}_{1}\right)$ may be accepted, as it was found that the use of a miniscrew in the retromolar area and a mesial button on the crown straightened the second molar significantly $(p=0.005)$. 
In all the cases included in this clinical series, sufficient prosthetic space was gained to allow replacement of the missing molar with an implant-supported single crown. The space gained was also statistically significant $(p=0.005)$.

Although other studies do not provide actual data regarding the prosthetic space gained, they do report sufficient gains to allow replacement of the missing tooth with an implant $[23,30,33]$. Meanwhile, Lee et al. [29], after straightening the mesialized tooth, closed the space by means of conventional orthodontic movement. Musilli et al. [23] state that treatment obtained sufficient space to replace the missing tooth although they do not specify the rehabilitation provided. The second hypothesis $\left(\mathrm{H}_{2}\right)$ that miniscrews would produce enough prosthetic space to replace the first molar may also be accepted.

There are many techniques for molar uprighting, such as: Australian uprighting spring, cantilever spring, prefabricated Sander spring, helical uprighting spring, NiTi coil spring, push spring appliance, or orthodontic miniscrew implants, among others [34].

Molar uprighting requires good anchorage control, and conventional treatment methods have some disadvantages: a full arch fixed appliance is necessary to minimize the extrusion of the target molar and the reciprocal movement of the anchorage units; spring designs require complex mechanics and may cause tissue irritation to the patient [35]; in addition, longer treatment time and bulky appliances are needed. Miniscrews are simpler, smaller, less invasive, more economical, and do not require a long interval between placement and force application, since loading can occur immediately after placement. Their main advantage is their ability to move specific teeth without involving other teeth or using inter arch mechanics [34]. However, the stability of the miniscrew is influenced by their insertion sites; it has been described [36] that the failure rate for miniscrews inserted in the interradicular space is higher than that in the retromolar area. In this case series, in which miniscrews were located in the retromolar area, none of them suffered loss of mechanical anchorage until the end of the straightening of the inclined molars. Due to numerous advantages and according to a systematic review of the literature, miniscrews seem to constitute a reliable solution for treating tipped or impacted molars [37].

The main clinical involvement of the use of miniscrews in the retromolar area is the considerable improvement in the position of the second molar present after the absence of the first molar, increasing the restorable distal mean prosthetic space and handling correct prosthetic spaces for the replacement of the molar absent by dental implants. In addition, it is possible to avoid the retention of food and dental plaque that the open space can generate when the second molar is poorly positioned, and the prosthesis cannot seal it. All these improvements can be obtained in a short time (2-3 months usually) without the need to associate with orthodontic treatments in those patients who do not require it. Patients are also more satisfied with the more invisible treatment compared to conventional methods.

The present clinical series suffered certain limitations. A larger sample size would have been preferable in order to amplify the quantity of data for analysis. Moreover, posttreatment follow-up would make it possible to assess the medium- to long-term prognosis of the treatment. This is a preliminary study to analyze the behavior of miniscrews on which it is intended to increase the sample and the follow-up time in the future. More studies of the use of miniscrews for straightening molars and producing adequate prosthetic space to replace missing teeth are needed.

\section{Conclusions}

According to the results obtained, it may be concluded that:

1. The use of miniscrews improves posterior dental angulation and available prosthetic space significantly;

2. The correlation between the increase in prosthetic space and improved angulation is very strong;

3. The technique may be considered very useful in prosthodontics, as it avoids subjecting the patient to the intervention of other orthodontic treatment. 
Author Contributions: Conceptualization, A.R.-V., N.B.-H., E.S.-O. and R.A.-P.; methodology, C.F.-B. and M.F.S.-R.; formal analysis, M.F.S.-R.; investigation, A.R.-V., N.B.-H., and R.A.-P.; data curation E.S.-O.; writing—original draft preparation, N.B.-H.; writing—review and editing, A.R.-V., N.B.-H., and R.A.-P.; supervision A.R.-V. and R.A.-P. All authors have read and agreed to the published version of the manuscript.

Funding: This research received no external funding.

Institutional Review Board Statement: The study was conducted according to the guidelines of the Declaration of Helsinki, and approved by the Institutional Review Board (or Ethics Committee) of University of Valencia (Procedure $N^{\circ}$ H1510309932301. 2 September 2019).

Informed Consent Statement: Informed consent was obtained from all subjects involved in the study. Informed written consent has been obtained from patients to publish this article.

Conflicts of Interest: The authors declare no conflict of interest.

\section{References}

1. Raveli, T.B.; Raveli, D.B.; de Mathias Almeida, K.C.; dos Santos Pinto, A. Molar Uprighting: A Considerable and Safe Decision to Avoid Prosthetic Treatment. Open Dent. J. 2017, 11, 466-475. [CrossRef] [PubMed]

2. D'Souza, I.; Kumar, K.; Shetty, K. Uprighting of molars-A clinical challenge. Virtual J. Orthod. 2013, $201,1-18$.

3. Martires, S.; Kamat, N.V.; Dessai, S.R. A CBCT evaluation of molar uprighting by conventional versus microimplant-assisted methods: An in-vivo study. Dental Press J. Orthod. 2018, 23, 35.e1-35.e9. [CrossRef] [PubMed]

4. Zhou, J.; Gan, X.; Han, X.; Razzoog, M.E.; Zhu, Z. Uprighting a mesially tilted mandibular left second molar with anchorage from a dental implant. J. Prosthet. Dent. 2020, 123, 50-53. [CrossRef]

5. Stern, N.; Revah, A.; Becker, A. The tilted posterior tooth. Part I: Etiology, syndrome, and prevention. J. Prosthet. Dent. 1981, 46, 404-407. [CrossRef]

6. Norton, L. Periodontal considerations in orthodontic treatment. Dent. Clin. N. Am. 1981, 25, 117-130. [PubMed]

7. Sawicka, M.; Racka-Pilszak, B.; Rosnowska-Mazurkiewicz, A. Uprighting Partially Impacted Permanent Second Molars. Angle Orthod. 2007, 77, 148-154. [CrossRef]

8. Mah, S.-J.; Won, P.-J.; Nam, J.-H.; Kim, E.-C.; Kang, Y.-G. Uprighting mesially impacted mandibular molars with 2 miniscrews. Am. J. Orthod. Dentofac. Orthop. 2015, 148, 849-861. [CrossRef]

9. Hjalmarsson, L.; Gheisarifar, M.; Jemt, T. A systematic review of survival of single implants as presented in longitudinal studies with a follow-up of at least 10 years. Eur. J. Oral Implantol. 2016, 9, 155-162.

10. Zachrisson, B.; Bantleon, H. Optimal mechanics for mandibular molar uprighting. World J. Orthod. 2005, 6, 80-87.

11. Shellhart, W.C.; Oesterle, L.J. Uprighting molars without extrusion. J. Am. Dental Assoc. 1999, 130, 381-385. [CrossRef] [PubMed]

12. Viecilli, R.F.; Chen, J.; Katona, T.R.; Roberts, W.E. Force system generated by an adjustable molar root movement mechanism. Am. J. Orthod. Dentofac. Orthop. 2009, 135, 165-173. [CrossRef] [PubMed]

13. Resnik, R. Misch's Contemporary Implant Dentistry, 4th ed.; Mosby/Elsevier Inc.: St Louis, MO USA, 2020.

14. Chen, C.-H.; Chang, C.-S.; Hsieh, C.-H.; Tseng, Y.-C.; Shen, Y.-S.; Huang, I.-Y.; Yang, C.-F.; Chen, C.-M. The Use of Microimplants in Orthodontic Anchorage. J. Oral Maxillofac. Surg. 2006, 64, 1209-1213. [CrossRef] [PubMed]

15. Sohn, D.-S.; Lee, J.-K.; An, K.-M. Minor Tooth Movements Using Microimplant Anchorage: Case Reports. Implant Dent. 2008, 17, 32-39. [CrossRef] [PubMed]

16. Chen, Y.-H.; Chang, H.-H.; Chen, Y.-J.; Lee, D.; Chiang, H.-H.; Jane Yao, C.-C. Root contact during insertion of miniscrews for orthodontic anchorage increases the failure rate: An animal study. Clin. Oral Implant. Res. 2008, 19, 99-106. [CrossRef] [PubMed]

17. Cho, U.-H.; Yu, W.; Kyung, H.-M. Root Contact during Drilling for Microimplant Placement. Angle Orthod. 2010, 80, 130-136. [CrossRef]

18. Hwang, Y.-C.; Hwang, H.-S. Surgical repair of root perforation caused by an orthodontic miniscrew implant. Am. J. Orthod. Dentofac. Orthop. 2011, 139, 407-411. [CrossRef]

19. Suzuki, M.; Deguchi, T.; Watanabe, H.; Seiryu, M.; Iikubo, M.; Sasano, T.; Fujiyama, K.; Takano-Yamamoto, T. Evaluation of optimal length and insertion torque for miniscrews. Am. J. Orthod. Dentofac. Orthop. 2013, 144, 251-259. [CrossRef]

20. Papadopoulos, M.A.; Tarawneh, F. The use of miniscrew implants for temporary skeletal anchorage in orthodontics: A comprehensive review. Oral Surg. Oral Med. Oral Pathol. Oral Radiol. Endodontol. 2007, 103, e6-e15. [CrossRef]

21. Ruellas, A.C.D.O.; Pithon, M.M.; Santos, R.L.D. Miniscrew-supported coil spring for molar uprighting: Description. Dental Press J. Orthod. 2013, 18, 45-49. [CrossRef]

22. Cernei, E.; Mavru, R.; Zetui, I. Second molar uprighting after premature loss of mandibular first permanent molar-Case report. Med. Surg. J. 2015, 119, 572-578.

23. Musilli, M.; Marsico, M.; Romanucci, A.; Grampone, F. Molar uprighting with mini screws: Comparison among different systems and relative biomechanical analysis. Prog. Orthod. 2010, 11, 166-173. [CrossRef] [PubMed]

24. Piao, C.M.; Lee, J.E.; Koak, J.Y.; Kim, S.K.; Rhyu, I.C.; Han, C.H.; Herr, Y.; Heo, S.J. Marginal bone loss around three different implant systems: Radiographic evaluation after 1 year. J. Oral Rehabil. 2009, 36, 748-754. [CrossRef] [PubMed] 
25. Peñarrocha-Diago, M.A.; Flichy-Fernández, A.J.; Alonso-González, R.; Peñarrocha-Oltra, D.; Balaguer-Martínez, J.; PeñarrochaDiago, M. Influence of implant neck design and implant-abutment connection type on peri-implant health. Radiological study. Clin. Oral Implant. Res. 2012, 24, 1192-1200. [CrossRef] [PubMed]

26. Spinato, S.; Galindo-Moreno, P.; Bernardello, F.; Zaffe, D. Minimum Abutment Height to Eliminate Bone Loss: Influence of Implant Neck Design and Platform Switching. Int. J. Oral Maxillofac Implant. 2018, 33, 405-411. [CrossRef] [PubMed]

27. Agustín-Panadero, R.; León-Martínez, R.; Labaig-Rueda, C.; Faus-López, J.; Solá-Ruíz, M. Influence of Implant-Prosthetic Connection on Peri-implant Bone Loss: A Prospective Clinical Trial with 2-Year Follow-up. Int. J. Oral Maxillofac Implant. 2019, 34, 963-968. [CrossRef]

28. Agustín-Panadero, R.; Bustamante-Hernández, N.; Solá-Ruíz, M.F.; Zubizarreta-Macho, Á.; Fons-Font, A.; Fernández-Estevan, L. Influence of Biologically Oriented Preparation Technique on Peri-Implant Tissues; Prospective Randomized Clinical Trial with Three-Year Follow-Up. Part I: Hard Tissues. J. Clin. Med. 2019, 8, 2183. [CrossRef]

29. Lee, K.; Park, Y.; Hwang, W.; Seong, E. Uprighting mandibular second molars with direct miniscrew anchorage. J. Clin. Orthod. 2007, 41, 627-635.

30. Greco, M.; Meddis, V.; Giancotti, A. The G-chain and miniscrew anchorage: Simple mechanics for molar uprighting. J. Clin. Orthod. 2012, 46, 24-25.

31. Park, H.; Kyung, H.; Sung, J. A simple method of molar uprighting with micro-implant anchorage. J. Clin. Orthod. 2002, 36, 592-596.

32. Derton, N.; Perini, A.; Mutinelli, S.; Gracco, A. Mandibular molar uprighting using mini-implants: Different approaches for different clinical cases-Two case reports. Orthod. Art Pract. Dentofac. Enhanc. 2012, 13, 138-145.

33. Melo, A.; Duarte da Silva, R.; Shimizu, R.; Campos, D.; Andrighetto, A. Lower molar uprighting with miniscrew anchorage: Direct and indirect anchorage. Int. J. Orthod Milwaukee 2013, 24, 9-14. [PubMed]

34. Magkavali-Trikka, P.; Emmanouilidis, G.; Papadopoulos, M.A. Mandibular molar uprighting using orthodontic miniscrew implants: A systematic review. Prog. Orthod. 2018, 19, 1. [CrossRef] [PubMed]

35. Tsironi, K.; Inglezos, E.; Vardas, E.; Mitsea, A. Uprighting an Impacted Permanent Mandibular First Molar Associated with a Dentigerous Cyst and a Missing Second Mandibular Molar-A Case Report. Dent. J. 2019, 7, 63. [CrossRef] [PubMed]

36. Chang, C.H.; Lin, J.S.; Roberts, W.H. Ramus screws: The ultimate solution for lower impacted molars. Semin. Orthod. 2018, 24, 135-154. [CrossRef]

37. Morita, Y.; Koga, Y.; Nguyen, T.A.; Yoshida, N. Biomechanical considerations for uprighting impacted mandibular molars. Korean J. Orthod. 2020, 50, 268-277. [CrossRef] 